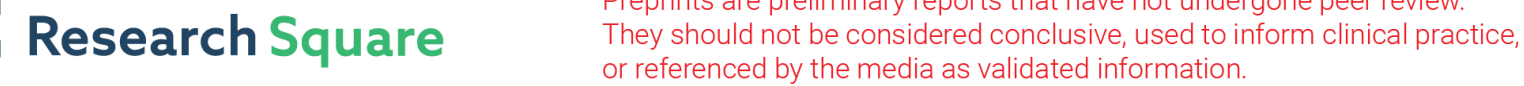 \\ Preprints are preliminary reports that have not undergone peer review.
}

\section{Association Between PFOA Exposure and Liver Enzymes: a Systematic Review and Meta-analysis of Longitudinal Cohort Studies}

\author{
Tian-Qi Wang \\ First Affiliated Hospital of Anhui Medical University \\ Yue-Nan Chen \\ Anhui Medical University \\ Si-Yu Gui \\ Second Affiliated Hospital of Anhui Medical University \\ Zheng-Xuan Jiang \\ Second Affiliated Hospital of Anhui Medical University \\ Ze-Lian Li \\ First Affiliated Hospital of Anhui Medical University \\ Heng Jiang \\ Second Affiliated Hospital of Anhui Medical University \\ Chao Zhang ( $\left.\nabla_{\mathrm{m} 18788877170 @ 163 . c o m}\right)$ \\ Anhui Medical University https://orcid.org/0000-0001-9044-3566
}

Research

Keywords: Perfluoroalkyl substances, PFOA, Liver enzyme, Systematic review, Meta-analys

Posted Date: September 15th, 2021

DOI: https://doi.org/10.21203/rs.3.rs-853167/v1

License: (c) (i) This work is licensed under a Creative Commons Attribution 4.0 International License. Read Full License 


\section{Abstract}

Background: Perfluorooctanoic acid (PFOA) has been the focus of research regarding its effects on liver function due to its potential for bioaccumulation in human body, widespread exposure, and the ability acting as an endocrine disruptor. Although the hepatotoxicity of PFOA has been identified, conclusions from population-based studies remain inconsistent, and the purpose of this study was to systematically review the epidemiological evidence linking PFOA to the four most common liver enzyme indicators and to quantitatively pool the effects of existing longitudinal cohort studies.

Methods: Longitudinal cohort studies on PFOA and the four liver enzyme indicators (alanine aminotransferase (ALT), aspartate aminotransferase (AST), gamma-glutamyl transferase (GGT) and alkaline phosphatase (ALP)) were searched in three electronic databases (PubMed, Web of Science and EMBASE) until July 10, 2021. Random-effects meta-analysis was used to calculate pooled effect estimates for continuous exposure. We also assessed the risk of study bias and the overall quality and level of evidence for each exposure and outcome combination.

Results: The initial search identified 18 studies, 9 of which were eventually included. PFOA showed significant relationships with all four liver enzyme metrics: $\operatorname{ALT}(N=7, \beta=0.012,0.001-0.023)$, AST ( $N=6, \beta=0.041,0.002-0.079), G G T(N=6, \beta=0.010,0.001-0.020), A L P(N=4, \beta=0.007,0.002-0.011)$ with low to high concomitant heterogeneity. The certainty of the combined evidence for each exposure-outcome combination was considered "moderate".

Conclusions: We conducted the first meta-analysis and systematic review based on a longitudinal cohort study, and the results support the hypothesis that PFOA increases levels of four common liver enzymes, and that this causal relationship was observed within the context of a population-based study area. Further clinical or epidemiological research, especially longitudinal studies, are needed to expand the sample size and further determine the effect of different types and doses of confounders of PFOA exposure on liver enzyme indices, with adequate consideration of sex, age, and other confounders as well as reverse causality.

\section{Introduction}

Perfluorooctanoic acid (PFOA) is one of the most used perfluoroalkyl acid (PFAA) class of chemicals, an environmentally widespread fluoropolymer [1], characterized by high stability and persistence, which is widely used in food packaging, furniture, textiles, and other commercial manufacturing applications [2] on account of its surfactant property. However, environmental and health issues related to PFOA have attracted increasing public attention in recent years, and an increasing number of experimental studies have revealed the extensive deposition of PFOA in serum and liver after absorption by humans, as well as the long half-life and hyper-biotoxicity, especially hepatotoxicity, as a typical endocrine disruptor [3, 4]. Extensive population-based epidemiological studies have identified its possible association with adverse birth liver disease, pancreatic cancer, biliary obstruction, and other liver diseases such as hepatocellular carcinoma, and the association of biological markers including liver enzymes, bilirubin, and lipid level markers with PFOA has been routinely reported [5-7]. A community study in $[8]$ and a longitudinal cohort study in $[9,10]$ both found a linear positive association between PFOA serum levels and simultaneously measured ALT, AST, and GGT concentrations, and this relationship was validated in another National Health and Nutrition Examination study (NHANES) [11], but $[12,13]$ and [9] failed to detect this effect and [14] even found an inverse association between ALP and PFOA, and it is worth noting that most current epidemiological studies have clustered in cross-sectional studies and small occupational population cohort studies [15]. Despite the fact that many developed countries especially in the United States have banned industrial PFOA emissions and manufactured new short-chain alternatives with similar efficacy, the high bio-chain accumulation of PFOA and its non-degradable character result in varying levels of PFOA still being detectable in the serum of most humans, even in the Arctic [16-19].

Since the four biological liver enzymes (ALT, AST, ALP, GGT) are the most important biological enzymes reflecting liver function and disease severity, they are also the most commonly used clinical indicators of liver function and are capable of playing an important auxiliary diagnostic role in the areas including hepatocellular injury and hepatitis (ALT, AST, albumin), biliary tract disease and bile duct obstruction (ALP, GGT), bile secretion and lipid metabolism (bilirubin) [20,21]. Besides, these four liver enzyme activities become generally elevated in extrahepatic diseases such as syphilis [22] and obesity [23], and a cohort study revealed that ALT, AST and GGT levels were significantly higher in patients with severe COVID-19 than in those without severe disease [24, 25]. However, environmental factors such as persistent pollutants (e.g., PFOA, PFOS) with liver enzymes has still lacked sufficient attention [11, 12, 15]. Animal experiments have shown multiple potential mechanisms suggesting the role of PFOA in altering liver enzyme levels, including that exposure to PFOS significantly enhances the expression of various genes in the mTOR signaling pathway, disrupting specific biotransformation pathways [26, 27]. Yi Wen et al. [28] found considerable inhibitory effects on both anti-apoptotic and lipid metabolism genes in HepG2 hepatocytes after $48 \mathrm{~h}$ exposure to PFOA, and [12] and [29] also demonstrated lipid regulation, multiple hormone regulation and hepatocyte metabolic toxicity of PFOA in rodents. In contrast, population-based studies remain inconsistent, a 10-year U.S. population study found that changes in liver enzyme levels with PFOA exposure corresponded to different stages of renal function [30], Most cross-sectional studies have found that PFOA exposure is not accompanied by statistically significant changes in liver enzymes [8, 10, 11]. Therefore, it remains controversial whether population-based studies of PFOA exposure cause changes in liver enzyme levels [15].

Considering the current small sample size of individual epidemiological studies and the methodological differences in exposure and liver enzyme measurements, inconsistencies in the selection of study contexts and populations as well as the large number of cross-sectional studies that may have confounded potential causality determination, these may have contributed to the conflicting findings of epidemiological studies of PFOA and liver enzyme levels $[10,15,31,32]$. Of environmental epidemiology research, systematic reviews and meta-analyses (SRMAs) are increasingly applied to quantitatively combining data across studies and assisting in translating evidence into policies. Sparse data were available on the relevance of PFOA and liver enzyme, not even systematic reviews as well as meta-analyses during the literature search. Although the overall volume of relevant literature is encouraging, the number of studies assigned to specific combinations of different exposure outcomes is inadequate.

Therefore, our study aims to address these inconsistent findings and summarize the latest evidence from longitudinal cohort-based studies in a more standardized and detailed format to provide policymakers and healthcare providers with a more comprehensive assessment of the association between PFOA 
and liver enzyme indicators, thereby improving the preventive health of the public.

\section{Materials And Methods}

\subsection{Search strategy}

Our reporting process is in accordance with the Preferred Reporting Items for Systematic Reviews and Meta-Analyses (PRISMA) statement guidelines [33] (Table S1). Initially, we formulated a specific research question based on the PECOS (Population, Exposure, Comparator, Outcome, Study) principles as follows "Do the levels of the four liver enzymes (ALT, AST, GGT and ALP) change (outcome) in people (population) when exposed or presenting with PFOA (exposure) compared with all people not exposed to PFOA or at low risk/level of exposure to PFOA (comparators) based on cohorts (study design)? " We used the Web of Science, PubMed and EMBASE databases for search using terms: (PFOA OR pfoa OR Perfluorooctanoic Acid OR Pentadecafluorooctanoic acid OR Perfluorocaprylic acid) and (liver enzyme* OR hepatase OR hepatic enzyme* OR ALT OR Alanine transaminase OR AST OR aspartate transaminase OR GGT OR gamma-glutamyl transferase OR ALP OR alkaline phosphatase) applied to ascertain the relevant studies. The search criteria were not restricted to language and were last updated on July 10, 2021. The specific search methods and results are shown in (Table S2).

\subsection{Study selection}

Following the guidance of the PECOS statement we have established the following eligibility criteria: (P): People exposed to perfluorinated compounds (living, working or schooling in the factory, near contaminated water, in a contaminated atmosphere, etc.); (E): Exposed to PFOA OR pfoa OR Perfluorooctanoic Acid

OR Perfluorocaprylic acid in the body (body fluids, e.g., serum, plasma, etc.); (C): Individuals assessed as non-exposed or at low risk/level of exposure to PFOA; (O): Levels of four enzymes including ALT, AST, GGT, and ALP; (S): All cohorts, cohort-based reports with well-documented data were regarded as qualified for review. Firstly, we collected the searched literature and independently filtered the complete titles and abstracts after removing duplicates; after the initial screening, we downloaded the full text of the initial screened literature and secondary screened to decide whether the literature should be retained or removed via a thorough evaluation. All disagreements during this period will be resolved through group discussions.

\subsection{Data extraction and quality assessment}

The author extracted the data independently using a predefined data template. We focused on the analysis of the association between PFOA and the four liver enzyme indicators. The characteristics of the extracted eligible studies are shown in (Table 1). On this basis, the first author/corresponding of the selected study will be communicated with to obtain necessary data that are missing or cannot be extracted from their supplementary material or relevant publications. We assessed the quality of each study using the corrected list used in the [34]. The list was divided into three panels of high, medium, and low quality (quality scores of 1.00 to $0.80,0.79$ to 0.60 and $<0.60$, respectively). Each element of the list was scored 0.00 to 1.00 , then the total score for all elements of each study was calculated, and finally the unit-weighted quality score was calculated (Table S3). 
Table 1

Characteristics of included studies examining the association between PFOA with liver enzymes.

\begin{tabular}{|c|c|c|c|c|c|c|c|c|c|c|c|}
\hline $\begin{array}{l}\text { Author } \\
\text { (year) }\end{array}$ & Setting & $\begin{array}{l}\text { Study } \\
\text { design }\end{array}$ & $\mathbf{N}$ & $\begin{array}{l}\text { Population } \\
\text { demographics }\end{array}$ & Sex & $\begin{array}{l}\text { PFAS types: } \\
\text { conc. and } \\
\text { spread (ng/ml) }\end{array}$ & $\begin{array}{l}\text { Outcome } \\
\text { assessment }\end{array}$ & $\begin{array}{l}\text { Liver } \\
\text { function/ } \\
\text { Definitions }\end{array}$ & $\begin{array}{l}\text { Effect } \\
\text { size }\end{array}$ & $\begin{array}{l}\text { Units of } \\
\text { effect size }\end{array}$ & $\begin{array}{l}\text { Adjusted } \\
\text { for:age }\end{array}$ \\
\hline $\begin{array}{l}\text { Lyndsey } \\
\text { A. } \\
\text { Darrow } \\
\text { (2016) }\end{array}$ & $\begin{array}{l}\text { United } \\
\text { States }\end{array}$ & cohort & 32254 & $\begin{array}{l}\text { C8 Health } \\
\text { Project }\end{array}$ & all & PFOA:2.6-81.5 & Report & $\begin{array}{l}\text { ALT(IU/L) } \\
\text { GGT } \\
(\mathrm{IU} / \mathrm{L})\end{array}$ & $\beta$ & $\begin{array}{l}\text { per log- } \\
\text { unit }(\mathrm{ng} / \mathrm{ml}) \text {, } \\
\text { per } \\
\text { IQR (ng/ml) }\end{array}$ & Yes \\
\hline $\begin{array}{l}\text { Edward } \\
\text { Anthony } \\
\text { Emmett } \\
(2006)\end{array}$ & America & cohort & 371 & $\begin{array}{l}\text { Little Hocking } \\
\text { Water } \\
\text { Association } \\
\text { district }\end{array}$ & all & $\begin{array}{l}\text { PFOA:354(184- } \\
571)\end{array}$ & Report & $\begin{array}{l}\text { ALP(U/L) } \\
\text { AST (U/L) } \\
\text { GGT (U/L) }\end{array}$ & $\beta$ & $\begin{array}{l}\text { per } \\
\text { IQR (ng/ml) }\end{array}$ & No \\
\hline $\begin{array}{l}\text { Chien- } \\
\text { Yu Lin } \\
(2010)\end{array}$ & $\begin{array}{l}\text { United } \\
\text { States }\end{array}$ & cohort & 2216 & $\begin{array}{l}\text { National } \\
\text { Health and } \\
\text { Nutrition } \\
\text { Examination } \\
\text { Survey } \\
\text { (NHANES) }\end{array}$ & $\begin{array}{l}\text { Male } \\
\text { Female }\end{array}$ & $\begin{array}{l}\text { PFOA:2.90- } \\
5.95 \\
\text { PFNA:0.40- } \\
1.20 \\
\text { PFHxS:1.10- } \\
3.10 \\
\text { PFOS:15.50- } \\
33.80\end{array}$ & Report & $\begin{array}{l}\operatorname{ALT}(\mathrm{U} / \mathrm{L}) \\
\mathrm{GGT}(\mathrm{U} / \mathrm{L})\end{array}$ & $\beta$ & $\begin{array}{l}\text { per log- } \\
\text { unit }(\mathrm{ng} / \mathrm{ml})\end{array}$ & Yes \\
\hline $\begin{array}{l}\text { Ana M. } \\
\text { Mora } \\
\text { (2018) }\end{array}$ & America & cohort & 682 & $\begin{array}{l}\text { Boston-area } \\
\text { pre-birth } \\
\text { cohort. }\end{array}$ & $\begin{array}{l}\text { Male } \\
\text { Female }\end{array}$ & $\begin{array}{l}\text { PFOA: } 5.4(3.9- \\
7.6) \\
\text { PFOS: } 24.6 \\
(17.9-34) \\
\text { PFNA:0.6 (0.5- } \\
0.9) \\
\text { PFHxS: } 2.4 \\
(1.6-3.8)\end{array}$ & Report & $\operatorname{ALT}(\mathrm{U} / \mathrm{L})$ & $\beta$ & $\begin{array}{l}\text { per } \\
\text { IQR (ng/ml) }\end{array}$ & Yes \\
\hline $\begin{array}{l}\text { Min } \\
\text { Nian } \\
(2019)\end{array}$ & China & cohort & 1605 & $\begin{array}{l}\text { The Isomers of } \\
\text { C8 Health } \\
\text { Project in } \\
\text { China }\end{array}$ & all & $\begin{array}{l}\text { PFOA: } 6.19 \\
(4.08-9.31) \\
\text { PFOS: } 24.22 \\
(14.62-37.19)\end{array}$ & Report & $\begin{array}{l}\operatorname{ALP}(\mathrm{U} / \mathrm{L}) \\
\operatorname{ALT}(\mathrm{U} / \mathrm{L}) \\
\text { AST (U/L) } \\
\text { GGT (U/L) }\end{array}$ & $\beta$ & $\begin{array}{l}\text { per In- } \\
\text { unit (ng/ml) }\end{array}$ & Yes \\
\hline $\begin{array}{l}\text { Geary } \\
\text { W. } \\
\text { Olsen } \\
(2000)\end{array}$ & America & cohort & 74 & $\begin{array}{l}\text { Voluntary } \\
\text { medical } \\
\text { surveillance } \\
\text { examinations }\end{array}$ & all & $\begin{array}{l}\text { PFOA:1.3(0.1- } \\
81.3)\end{array}$ & Report & $\begin{array}{l}\text { ALP(IU/L) } \\
\text { ALT(IU/L) } \\
\text { AST (IU/L) } \\
\text { GGT } \\
\text { (IU/L) }\end{array}$ & $\beta$ & $\begin{array}{l}\text { per } \\
\text { IQR (ng/ml) }\end{array}$ & Yes \\
\hline $\begin{array}{l}\text { Geary } \\
\text { W. } \\
\text { Olsen } \\
(2007)\end{array}$ & America & cohort & 506 & $\begin{array}{l}\text { Fluorochemical } \\
\text { medical } \\
\text { surveillance } \\
\text { program }\end{array}$ & all & $\begin{array}{l}\text { PFOA:1.10 } \\
0.01-92.03\end{array}$ & Report & $\begin{array}{l}\text { ALT(IU/L) } \\
\text { AST (IU/L) } \\
\text { GGT } \\
(\text { IU/L) }\end{array}$ & $\beta$ & $\begin{array}{l}\text { per ln- } \\
\text { unit }(\mathrm{ng} / \mathrm{ml})\end{array}$ & Yes \\
\hline
\end{tabular}




\begin{tabular}{|c|c|c|c|c|c|c|c|c|c|c|c|}
\hline $\begin{array}{l}\text { Author } \\
\text { (year) }\end{array}$ & Setting & $\begin{array}{l}\text { Study } \\
\text { design }\end{array}$ & $\mathrm{N}$ & $\begin{array}{l}\text { Population } \\
\text { demographics }\end{array}$ & Sex & $\begin{array}{l}\text { PFAS types: } \\
\text { conc. and } \\
\text { spread (ng/ml) }\end{array}$ & $\begin{array}{l}\text { Outcome } \\
\text { assessment }\end{array}$ & $\begin{array}{l}\text { Liver } \\
\text { function/ } \\
\text { Definitions }\end{array}$ & $\begin{array}{l}\text { Effect } \\
\text { size }\end{array}$ & $\begin{array}{l}\text { Units of } \\
\text { effect size }\end{array}$ & $\begin{array}{l}\text { Adjusted } \\
\text { for:age }\end{array}$ \\
\hline \multirow{2}{*}{$\begin{array}{l}\text { Geary } \\
\text { W. } \\
\text { Olsen } \\
(2012)\end{array}$} & \multirow[t]{2}{*}{ America } & \multirow[t]{2}{*}{ cohort } & \multirow[t]{2}{*}{179} & \multirow{2}{*}{$\begin{array}{l}\text { Fluorochemical } \\
\text { medical } \\
\text { surveillance } \\
\text { program }\end{array}$} & \multirow[t]{2}{*}{ all } & $\begin{array}{l}\text { PFOA: } 50.9 \\
(106.9)\end{array}$ & \multirow[t]{2}{*}{ Report } & ALP(IU/L) & \multirow[t]{2}{*}{$\beta$} & \multirow[t]{2}{*}{$\begin{array}{l}\text { per log- } \\
\text { unit (ng/ml) }\end{array}$} & \multirow[t]{2}{*}{ Yes } \\
\hline & & & & & & $\begin{array}{l}\text { PFOS: } 6.2 \\
(11.2)\end{array}$ & & AST (IU/L) & & & \\
\hline \multirow{2}{*}{$\begin{array}{l}\text { Jianshe } \\
\text { Wang } \\
\text { (2012) }\end{array}$} & \multirow[t]{2}{*}{ China } & \multirow[t]{2}{*}{ cohort } & \multirow[t]{2}{*}{420} & $\begin{array}{l}\text { Near the } \\
\text { Yangtze }\end{array}$ & \multirow[t]{2}{*}{ all } & \multirow[t]{2}{*}{$\begin{array}{l}\text { PFOA:34.6- } \\
284.34\end{array}$} & \multirow[t]{2}{*}{ Report } & ALT(IU/L) & \multirow[t]{2}{*}{$\beta$} & \multirow[t]{2}{*}{$\begin{array}{l}\text { per } \mathrm{In-} \\
\text { unit }(\mathrm{ng} / \mathrm{ml})\end{array}$} & \multirow[t]{2}{*}{ Yes } \\
\hline & & & & $\begin{array}{l}\text { River in a } \\
\text { suburban area } \\
\text { of Changshu } \\
\text { City, Jiangsu } \\
\text { Province. }\end{array}$ & & & & HOI (IU/L) & & & \\
\hline
\end{tabular}

\subsection{Risk of bias assessment}

We affirmed our conclusions by evaluating the risk of bias (RoB) for each study included in the meta-analysis. The RoB assessment describes the quality of the study and may indicate systematic errors in the results related to the assessment of methodological quality [35]. Individual human and animal studies were classified using the NTP/OHAT risk of bias assessment tool [36]. Three significant factors (confounding bias, exposure, and detection bias in outcome assessment) and four other factors (selection bias, selective reporting bias, consumption/exclusion bias and conflict of interest) were identified in observational studies. Each study assessed the risk of bias through a series of questions using "definitely low," "probably low," "probably high," or "definitely high" (see Table S4 for detailed questions and Table S5 for the rationale for each study's assessment). We identified the main confounding factors between continuous exposure (PFOA) and outcome according to [15], the domains classified as confounders in the study were assigned definitely high RoB if no or only one significant confounder (sex or age or alcohol or smoking or BIM) was considered; classified as probably high RoB if at least two of the following confounders (age or alcohol or smoking or BIM or educational attainment or income or sex) were considered; and classified as potentially probably low RoB if all of the above confounding factors were considered, the domain was classified as likely low RoB; if all of the above confounding factors and at least one of the following factors were considered (race; household income; regular exercise; fasting status; air pollution/noise; urbanization; greenness of residence) the domain was classified as definitely low RoB. Studies with potentially higher RoB ratings were assigned without sufficient information to determine RoB, and each study was classified as an overall level 1, 2, or 3 of RoB finally.

\subsection{Meta-analysis}

The purpose of the SRMA was to quantitatively assess the risk of PFOA exposure and four liver enzyme levels after combining the results of individual studies with appropriate integration. In this study, the included studies were all cohort studies, and the cross-sectional studies were excluded because the causal interpretation was limited by their design.

Pooled effect estimates were calculated unit change per $1 \mathrm{ng} / \mathrm{mL}$ or $\mathrm{ln}(\mathrm{ng} / \mathrm{mL})$ of PFOA for our meta-analysis. We performed meta-analyses of continuous exposures Since most studies on the relationship between PFOA and liver enzyme levels suggest a linear effect $[9,10]$, and the currently available data are insufficient for categorical exposure assessment (i.e., fourth percentile versus first percentile exposure, or third percentile versus first percentile exposure).

For continuous exposures, we selected their linear regression coefficients (LRC) or other effect sizes (ES) with standard errors (SE). Furthermore, we used ALP (IU/L), ALT (IU/L), AST (IU/L), and GGT (IU/L) as unified units of outcome indicators. Specific extraction data are shown in Supplementary Material B.

The effect estimates used for evidence synthesis were extracted from the "fully adjusted model" or "main model" from the included studies. If studies used the same population cohort and did not differ in composition and follow-up time, we therefore analyzed only the most recent date, whereas [14] reported different liver enzyme outcome indicators based on the same US birth cohort ([29], ALT, AST, GGT; [29], ALP, ALT, AST, GGT; [14], ALP, ALT, AST), and the effect size units were not identical (2007, per In-unit (ng/ml); 2000, per IQR (ng/ml); 2012, per log-unit (ng/ml)), with large differences in sample size (2007, $\mathrm{N}=506 ; 2000, \mathrm{~N}=$ $74 ; 2012, N=179$ ), therefore, these three studies were retained simultaneously for our further quantitative analysis. Similarly, where possible, maximally adjusted effect estimates (regression coefficients and $\beta$ ) were extracted; [37] reported $\Sigma$ PFOA, n-PFOA, iso-PFOA, we did not consider dividing the PFOA subgroup and only extracted the total PFOA; [9] reported different population cohorts $(N=1605, N=1176)$, we selected the later because it excluded drugtakers and reduced the risk of bias from confounders, similar situation was found in [29].

Based on the heterogeneity between studies, we performed a meta-analysis for each exposure-outcome combination in the form of random effects and fixed effects [15]. We used the $\mathrm{I}^{2}$ (greater than $50 \%$ is considered to indicate substantial heterogeneity) [38] and the P-value of the Chi-squared test for heterogeneity (less than 0.1 indicates statistical significance) [39] to assess heterogeneity. In addition, to identify sources of heterogeneity in the meta-analysis of included studies [38], pooled estimates were evaluated by subgroup analysis for consistency in whether adjusted for smoking, alcohol, and BMI, number of co-variate adjustments, and sample size, since the number of studies included in each of the four exposure outcome combinations was less than 10, preventing the possibility of meta-regression (Supplementary Material B). We also used the Egger test to assess publication bias [13]. Considering that statistical and graphical methods survive publication bias inaccuracy in some studies [40], Doi plots and Luis Furuya-Kanamori (LFK) indices (absolute value less than 1, "no asymmetry"; absolute value between 1 and 2, "slight asymmetry"; and absolute value greater than 2, "severe asymmetry") were evaluated. We performed sensitivity analyses to assess the stability of the results by sequentially excluding individual studies (the leave-one-out method) and recalculating the pooled

Page 5/18 
estimates. Stata version 14 (StataCorp LP, College Station, TX, USA) and MetaXL v.5.3 software (EpiGear International Pty Ltd, Sunrise Beach, Queensland, Australia, www.epigear.com) were used to perform all data analyses. For articles that did not fit the meta-analysis, we investigated and analyzed the relevant associations of the studies by descriptive summaries.

\subsection{Confidence ratings of evidence body and translation of evidence levels}

According to the updated NTP/ OHAT [41] and different exposure results, we assessed the body of evidence on the basis of the combined trust under the GRADE guidelines [42]. The NTP/OHAT framework was used to assess the quality and strength of the evidence because it was consistent with the causality criteria with Hill. In summary, observational studies exhibited low to moderate initial confidence ratings because of the lack of control for specified exposures. The initial confidence in the body of evidence was determined by key study design features. We assessed each exposure-outcome combination with four factors that increased initial confidence or five factors that decreased initial confidence. The final confidence for each exposure-outcome combination was categorized into four descriptors: "high" "moderate" "low" or "very low". The final confidence ratings of different combinations of exposure-outcomes will determine whether the level of evidence would be interpreted as "high", "moderate", "low", "insufficient" or "no evidence of health effects" level in epidemiological evidence.

\section{Results}

\subsection{Study selection and characteristics}

As shown in Fig. 1, we ultimately included nine relevant cohort study articles and pooled the available data on PFOA, and the four liver enzyme indicators provided in these studies for meta-analysis as well as systematic reviews $[9,15,38,39]$.

In Table 1, we summarize the characteristics of the included cohort studies. The years of publication ranged from 2006 to 2019 . Seven studies were from the United States, the other two from China. The minimum sample size of the included studies was 74 and the maximum sample size was 32,254 . Most studies did not provide data by gender subgroup, only two studies reported relevant data for both men and women respectively [10,39]. Of the continuous exposure data, seven studies were associated with ALT, four studies investigated ALP, two each of AST and GGT; for categorical exposure data, only one each of ALT and GGT was available $[15,29,38]$. All nine cohorts evaluated the relevant liver enzyme indicators by clinical examination reports, and eight studies adjusted for age and six studies adjusted for alcohol as independent confounder.

\subsection{Risk of bias assessment and study quality}

The results of the RoB assessment using heat maps are presented in Table 2. For the confounding bias assessment of the included studies, one was rated as "definitely low" ROB [15], four as "probably low" ROB, and three as "probably high" ROB [14, 29, 38, 40], because fewer major confounders or total confounders were included in the meta-analysis adjustment. For the assessment of detection bias, one study was classified as "definitely low" ROB in the assessment of exposure characterization [12] and eight studies as "probably low"; one study was "definitely low" in the ROB assessment of outcome characterization [38] and eight studies with "probably low". In the assessment of selection bias, four studies with "absolutely low" ROB [9, 10, 12, 15], as they were all cohort studies with large population sample sizes, and the remaining five cohort studies were rated as "probably low" ROB. For the assessment of attrition/exclusion bias, all included studies were rated as "probably low" RoB as there were no explicit exclusion bias. For selective reporting bias, one study was rated as "absolutely low" RoB [9], as the results included in the meta-analysis provided sufficient detail, and eight studies were rated as "probably low" RoB for indirect reporting of results. In the assessment of conflicts of interest, most authors declared no conflicts of interest, but two studies did not state whether there were conflicts of interest or financial support thus rated as "probably high" ROB $[13,14]$. In short, all eligible studies were categorized as either level $1(n=7)$ or level $2(n=2)$ of the RoB, demonstrating the presence of reasonable bias that might cast some doubt on the results. The studies included in our meta-analysis were cohort studies accompanied by relatively explicit exposure and outcome assessments with quality scores between 0.88 and 0.96 , so the quality of the studies we included can be considered high (Table S3). 
Table 2

Risk of bias rating for the included studies.

\begin{tabular}{|c|c|c|c|c|c|c|c|c|c|c|}
\hline \multicolumn{2}{|c|}{ Bias domain } & \multirow{5}{*}{$\begin{array}{l}\text { Lyndsey } \\
\text { A. Darrow } \\
\text { (2016) }\end{array}$} & \multirow{5}{*}{$\begin{array}{l}\text { Edward } \\
\text { Anthony } \\
\text { Emmett } \\
(2006)\end{array}$} & \multirow{5}{*}{$\begin{array}{l}\text { Chien- } \\
\text { Yu Lin } \\
\text { (2010) }\end{array}$} & \multirow{5}{*}{$\begin{array}{l}\text { Ana M. } \\
\text { Mora } \\
(2018)\end{array}$} & \multirow{5}{*}{$\begin{array}{l}\text { Min } \\
\text { Nian } \\
(2019)\end{array}$} & \multirow{5}{*}{$\begin{array}{l}\text { Geary } \\
\text { W. } \\
\text { Olsen } \\
(2000)\end{array}$} & \multirow{5}{*}{$\begin{array}{l}\text { Geary } \\
\text { W. } \\
\text { Olsen } \\
(2007)\end{array}$} & \multirow{5}{*}{$\begin{array}{l}\text { Geary } \\
\text { W. } \\
\text { Olsen } \\
(2012)\end{array}$} & \multirow{5}{*}{$\begin{array}{l}\text { Jianshe } \\
\text { Wang } \\
(2012)\end{array}$} \\
\hline++ & Definitively low risk of bias & & & & & & & & & \\
\hline+ & Probably low risk of bias & & & & & & & & & \\
\hline- & Probably high risk of bias & & & & & & & & & \\
\hline- & Definitively high risk of bias & & & & & & & & & \\
\hline \multicolumn{11}{|c|}{ Confounding bias } \\
\hline \multicolumn{2}{|c|}{$\begin{array}{l}\text { 1. Did the study design or analysis account for } \\
\text { important confounding and modifying } \\
\text { variables? (key domain) }\end{array}$} & ++ & - & + & + & + & + & - & - & - \\
\hline \multicolumn{11}{|c|}{ Detection bias } \\
\hline \multicolumn{2}{|c|}{$\begin{array}{l}\text { 1. Can we be confident in the exposure } \\
\text { characterization? (key domain) }\end{array}$} & + & + & + & ++ & + & + & + & + & + \\
\hline \multicolumn{2}{|c|}{$\begin{array}{l}\text { 2. Can we be confident in the outcome } \\
\text { assessment? (key domain) }\end{array}$} & + & + & + & + & + & + & + & + & ++ \\
\hline \multicolumn{11}{|c|}{ Selection bias } \\
\hline \multicolumn{2}{|c|}{$\begin{array}{l}\text { 1. Did selection of study participants result in } \\
\text { appropriate comparison groups? }\end{array}$} & ++ & + & ++ & ++ & ++ & + & + & + & + \\
\hline \multicolumn{11}{|c|}{ Attrition/Exclusion bias } \\
\hline \multicolumn{2}{|c|}{$\begin{array}{l}\text { 1. Were outcomes data complete without } \\
\text { attrition or exclusion from analysis? }\end{array}$} & + & + & + & + & + & + & + & + & + \\
\hline \multicolumn{11}{|c|}{ Selective reporting bias } \\
\hline \multicolumn{2}{|c|}{ 1. Were all measured outcome reported? } & + & + & + & + & ++ & + & + & + & + \\
\hline \multicolumn{11}{|c|}{ Other bias } \\
\hline \multicolumn{2}{|c|}{ 1. Conflict of interest } & + & + & + & + & + & - & - & - & + \\
\hline \multicolumn{2}{|c|}{ Summary tier category } & $\mathrm{T} 1$ & $\mathrm{~T} 1$ & $\mathrm{~T} 1$ & $\mathrm{~T} 1$ & $\mathrm{~T} 1$ & $\mathrm{~T} 1$ & $\mathrm{~T} 1$ & T2 & $\mathrm{T} 1$ \\
\hline
\end{tabular}

\subsection{Data synthesis}

\subsubsection{Meta-estimates of the relationship between PFOA and ALT}

Meta-analysis summarized effect estimates for per $1 \mathrm{ng} / \mathrm{ml}$ or $1 \mathrm{ln}(\mathrm{ng} / \mathrm{ml})$ increase in PFOA, and there was a statistically significant increase in ALT ( $\mathrm{n}=7, \beta=$ $0.012 \mathrm{IU} / \mathrm{L}, 95 \% \mathrm{Cl}: 0.001-0.023, \mathrm{P}=0.000$ ) with an overall $\mathrm{I}^{2}$ of $86.5 \%$ which showed the statistically significant heterogeneity; when introducing the exposure as high versus low categories, similar results were found, and there was a statistically significant increase $(n=1, \beta=0.048 \mathrm{IU} / \mathrm{L}, 95 \% \mathrm{Cl}$ : $0.031-0.066)$

(Table 3).

Table 3

Summary of meta-analyses of study on PFOA comparisons stratified by the diverse indicators of liver enzymes (IU/L) for continuous exposure.

\begin{tabular}{|c|c|c|c|c|c|c|c|}
\hline \multicolumn{2}{|c|}{ Liver enzymes indicators } & $\mathrm{N}$ studies & Summary $\beta$ or OR $(95 \% \mathrm{Cl})$ & P-value & I-squared & Tau-squared & Egger's test \\
\hline \multirow[t]{4}{*}{ PFOA } & ALT & 7 & $0.012(0.001,0.023)$ & 0.000 & $86.5 \%$ & 0.0001 & 0.959 \\
\hline & AST & 6 & $0.041(0.002,0.079)$ & 0.001 & $77.3 \%$ & 0.0012 & 0.060 \\
\hline & GGT & 6 & $0.010(0.001,0.020)$ & 0.001 & $75.4 \%$ & 0.0001 & 0.063 \\
\hline & ALP & 4 & $0.007(0.002,0.011)$ & 0.426 & $0.0 \%$ & 0.0000 & 0.303 \\
\hline
\end{tabular}

\subsubsection{Meta-estimates of the relationship between PFOA and AST}

Exposure to PFOA $(n=6, \beta=0.041 \mathrm{IU} / \mathrm{L}, 95 \% \mathrm{Cl}=0.002-0.079, \mathrm{P}=0.001)$ showed a statistically significant increase for per $1 \mathrm{ng} / \mathrm{ml}$ or $1 \mathrm{ln}(\mathrm{ng} / \mathrm{ml})$ increase in the six combinations associated with AST, with total 12 of $77.3 \%$ which shown the statistically significant heterogeneity (Table 3 ). 


\subsubsection{Meta-estimates of the relationship between PFOA and GGT}

Meta-analysis summarized the six combinations of study for per $1 \mathrm{ng} / \mathrm{ml}$ or $1 \mathrm{ln}(\mathrm{ng} / \mathrm{ml})$ increase in PFOA showed there was a statistically significant increase in GGT $(n=6, \beta=0.010 \mathrm{IU} / \mathrm{L}, 95 \% \mathrm{Cl}=0.001-0.020, P=0.001)$ accompanied with statistically significant heterogeneity $\left(\mathrm{I}^{2}=75.4 \%\right) ;$ when introducing the exposure as high versus low categories, similar results were found, and there was a statistically significant increase $(n=1, \beta=0.013$ IU/L, $95 \%$ Cl:-0.010-0.036) (Table 3).

\subsubsection{Meta-estimates of the relationship between PFOA and ALP}

Meta-analysis summarized the four combinations of study for per $1 \mathrm{ng} / \mathrm{ml}$ or $1 \mathrm{ln}(\mathrm{ng} / \mathrm{ml})$ increase in PFOA showed there was a statistically significant increase in $\operatorname{ALP}(n=4, \beta=0.007 \mathrm{IU} / \mathrm{L}, 95 \% \mathrm{Cl}=0.002-0.011, \mathrm{P}=0.000)$ accompanied with low heterogeneity $(\mathrm{I} 2=0.0 \%)(\mathrm{Table} 3)$.

\subsubsection{Analysis of subgroups}

By analyzing the data from the included studies, we established four subgroups of whether adjusted for alcohol, smoking or BMI, number of covariate adjustments, and sample size, to explore and assess the sources and characteristics of heterogeneity between exposure-outcome groups (Table 4). For alcohol intake, we found the significant association between PFOA and ALT ( $\beta=0.013$ ) as well as GGT ( $\beta=0.011)$ after confounding adjustment, but this relationship disappeared (GGT $\beta=0.000$ ) or even reversed (ALT $\beta=-0.176)$ for the unadjusted group, and we failed to identify significant association in this subgroup of AST and ALP. For whether adjust for the confounding factor of BMI, we failed to detect any significant association in any of the subgroups. For smoking, we found the significant association between PFOA and ALT $(\beta=0.010)$ after confounding adjustment, but this relationship disappeared ( $\beta=-0.074)$ for the unadjusted group, and we failed to identify significant association in other three liver enzyme indicators. Classified by the number of covariates adjusted, we observed significant associations of PFOA with AST ( $\beta=0.003)$, GGT $(\beta=0.003)$, and ALP $(\beta=0.007)$ in the number of $6-10$ group, similar situation occurred in AST $(\beta=0.027)$ after adjusting the number of covariates greater than 10 . By sample size, studies of PFOA and AST with sample size greater than the mean showed significant association $(\beta=0.027)$ but in contrast significant associations were found in the ALP groups with smaller sample sizes than the mean $(\beta=0.007)$ (Table 4$)$. 
Table 4

Summary regression coefficients $(\beta)$ and $95 \% \mathrm{Cl}$ by random effects meta-analysis stratified by different study characteristics.

\begin{tabular}{|c|c|c|c|c|c|c|}
\hline \multirow[t]{2}{*}{ Liver enzymes indicators } & \multirow[t]{2}{*}{ Study characteristics } & $\mathbf{N}$ & Summary $\beta$ or OR $(95 \% \mathrm{Cl})$ & $P$ value & I-squared & Tau-squared \\
\hline & & \multicolumn{5}{|c|}{ PFOA } \\
\hline \multirow[t]{16}{*}{ ALT } & sample size & 7 & $0.012(0.001,0.023)$ & 0.000 & $86.5 \%$ & 0.0001 \\
\hline & $>850$ & 2 & $0.027(-0.011,0.064)$ & 0.050 & $74.1 \%$ & 0.0006 \\
\hline & $<850$ & 5 & $-0.003(-0.033,0.027)$ & 0.000 & $84.1 \%$ & 0.0004 \\
\hline & Adjusted for: alcohol & 7 & $0.012(0.001,0.023)$ & 0.000 & $86.5 \%$ & 0.0001 \\
\hline & Yes & 5 & $0.013(0.004,0.022)$ & 0.000 & $86.4 \%$ & 0.0001 \\
\hline & No & 2 & $-0.176(-0.268,-0.083)$ & 0.580 & $0.0 \%$ & 0.0000 \\
\hline & Adjusted for: BMI & 7 & $0.012(0.001,0.023)$ & 0.000 & $86.5 \%$ & 0.0001 \\
\hline & Yes & 5 & $0.008(-0.003,0.020)$ & 0.000 & $88.6 \%$ & 0.0001 \\
\hline & No & 2 & $-0.057(-0.332,0.219)$ & 0.157 & $50.0 \%$ & 0.0264 \\
\hline & Adjusted for: smoking & 7 & $0.012(0.001,0.023)$ & 0.000 & $86.5 \%$ & 0.0001 \\
\hline & Yes & 4 & $0.010(0.000,0.019)$ & 0.000 & $87.1 \%$ & 0.0000 \\
\hline & No & 3 & $-0.074(-0.258,0.111)$ & 0.000 & $87.1 \%$ & 0.0170 \\
\hline & Number of co-variate adjustments & 7 & $0.012(0.001,0.023)$ & 0.000 & $86.5 \%$ & 0.0001 \\
\hline & $0-5$ & 3 & $-0.074(-0.258,0.111)$ & 0.000 & $87.7 \%$ & 0.0170 \\
\hline & $6-10$ & 2 & $-0.062(-0.305,0.182)$ & 0.187 & $42.6 \%$ & 0.0196 \\
\hline & $>10$ & 2 & $0.027(-0.011,0.064)$ & 0.050 & $74.1 \%$ & 0.0006 \\
\hline \multirow[t]{17}{*}{ AST } & sample size & 6 & $0.041(0.002,0.079)$ & 0.001 & $77.3 \%$ & 0.0012 \\
\hline & $>850$ & 1 & $0.027(0.001,0.052)$ & - & $0.0 \%$ & 0.0000 \\
\hline & $<850$ & 5 & $0.064(-0.010,0.138)$ & 0.001 & $78.6 \%$ & 0.0047 \\
\hline & Adjusted for: alcohol & 6 & $0.041(0.002,0.079)$ & 0.001 & $77.3 \%$ & 0.0012 \\
\hline & Yes & 4 & $0.017(-0.008,0.043)$ & 0.070 & $57.6 \%$ & 0.0003 \\
\hline & No & 2 & $0.100(-0.096,0.296)$ & 0.005 & $87.2 \%$ & 0.0174 \\
\hline & Adjusted for: BMI & 6 & $0.041(0.002,0.079)$ & 0.001 & $77.3 \%$ & 0.0012 \\
\hline & Yes & 4 & $0.041(-0.001,0.083)$ & 0.000 & $84.7 \%$ & 0.0012 \\
\hline & & 2 & & & & \\
\hline & No & & $0.062(-0.106,0.230)$ & 0.143 & $53.4 \%$ & 0.0086 \\
\hline & Adjusted for: smoking & 6 & $0.041(0.002,0.079)$ & 0.001 & $77.3 \%$ & 0.0012 \\
\hline & Yes & 2 & $0.011(-0.012,0.034)$ & 0.067 & $70.2 \%$ & 0.0002 \\
\hline & No & 4 & $0.093(-0.005,0.191)$ & 0.021 & $69.2 \%$ & 0.0065 \\
\hline & Number of co-variate adjustments & 6 & $0.041(0.002,0.079)$ & 0.001 & $77.3 \%$ & 0.0012 \\
\hline & $0-5$ & 4 & $0.093(-0.005,0.191)$ & 0.021 & $69.2 \%$ & 0.0065 \\
\hline & $6-10$ & 1 & $0.003(0.002,0.003)$ & - & $0.0 \%$ & 0.0000 \\
\hline & $>10$ & 1 & $0.027(0.001,0.052)$ & - & $0.0 \%$ & 0.0000 \\
\hline \multirow[t]{6}{*}{ GGT } & sample size & 6 & $0.010(0.001,0.020)$ & 0.001 & $75.4 \%$ & 0.0001 \\
\hline & $>850$ & 3 & $0.048(-0.012,0.108)$ & 0.000 & $88.1 \%$ & 0.0024 \\
\hline & $<850$ & 3 & $0.011(-0.010,0.032)$ & 0.203 & $37.3 \%$ & 0.0002 \\
\hline & Adjusted for: alcohol & 6 & $0.010(0.001,0.020)$ & 0.000 & $75.4 \%$ & 0.0001 \\
\hline & Yes & 5 & $0.011(0.001,0.021)$ & 0.000 & $80.3 \%$ & 0.0001 \\
\hline & No & 1 & $0.000(-0.166,0.166)$ & - & $0.0 \%$ & 0.0000 \\
\hline
\end{tabular}




\begin{tabular}{|c|c|c|c|c|c|c|}
\hline \multirow[t]{2}{*}{ Liver enzymes indicators } & \multirow[t]{2}{*}{ Study characteristics } & $\mathbf{N}$ & Summary $\beta$ or OR $(95 \% \mathrm{Cl})$ & $P$ value & I-squared & Tau-squared \\
\hline & & \multicolumn{5}{|c|}{ PFOA } \\
\hline & Adjusted for: BMI & 6 & $0.010(0.001,0.020)$ & 0.001 & $75.4 \%$ & 0.0001 \\
\hline & Yes & 4 & $0.008(-0.002,0.018)$ & 0.001 & $82.5 \%$ & 0.0001 \\
\hline & No & 2 & $0.031(-0.001,0.063)$ & 0.706 & $0.0 \%$ & 0.0000 \\
\hline & Adjusted for: smoking & 6 & $0.010(0.001,0.020)$ & 0.001 & $75.4 \%$ & 0.0001 \\
\hline & Yes & 4 & $0.008(-0.002,0.018)$ & 0.001 & $82.5 \%$ & 0.0001 \\
\hline & No & 2 & $0.031(-0.001,0.063)$ & 0.706 & $0.0 \%$ & 0.0000 \\
\hline & Number of co-variate adjustments & 6 & $0.010(0.001,0.020)$ & 0.001 & $75.4 \%$ & 0.0001 \\
\hline & $0-5$ & 2 & $0.031(-0.001,0.063)$ & 0.706 & $0.0 \%$ & 0.0000 \\
\hline & $6-10$ & 1 & $0.003(0.001,0.005)$ & - & $0.0 \%$ & 0.0000 \\
\hline & $>10$ & 3 & $0.048(-0.012,0.108)$ & 0.000 & $88.1 \%$ & 0.0024 \\
\hline \multirow[t]{17}{*}{ ALP } & sample size & 4 & $0.007(0.002,0.011)$ & 0.426 & $0.0 \%$ & 0.0000 \\
\hline & $>850$ & 1 & $-0.011(-0.034,0.012)$ & - & $0.0 \%$ & 0.0000 \\
\hline & $<850$ & 3 & $0.007(0.003,0.012)$ & 0.826 & $0.0 \%$ & 0.0000 \\
\hline & Adjusted for: alcohol & 4 & $0.007(0.002,0.011)$ & 0.426 & $0.0 \%$ & 0.0000 \\
\hline & Yes & 3 & $0.003(-0.010,0.016)$ & 0.248 & $28.2 \%$ & 0.0001 \\
\hline & No & 1 & $0.000(-0.357,0.357)$ & - & $0.0 \%$ & 0.0000 \\
\hline & Adjusted for: BMI & 4 & $0.007(0.002,0.011)$ & 0.426 & $0.0 \%$ & 0.0000 \\
\hline & Yes & 3 & $0.003(-0.010,0.016)$ & 0.248 & $28.2 \%$ & 0.0001 \\
\hline & No & 1 & $0.000(-0.357,0.357)$ & - & $0.0 \%$ & 0.0000 \\
\hline & Adjusted for: smoking & 4 & $0.007(0.002,0.011)$ & 0.426 & $0.0 \%$ & 0.0000 \\
\hline & Yes & 2 & $0.002(-0.015,0.018)$ & 0.121 & $0.0 \%$ & 0.0001 \\
\hline & No & 2 & $-0.048(-0.353,0.257)$ & 0.613 & $58.5 \%$ & 0.0000 \\
\hline & Number of co-variate adjustments & 4 & $0.007(0.002,0.011)$ & 0.426 & $0.0 \%$ & 0.0000 \\
\hline & $0-5$ & 2 & $-0.048(-0.353,0.257)$ & 0.613 & $0.0 \%$ & 0.0000 \\
\hline & $6-10$ & 1 & $0.007(0.003,0.012)$ & - & $0.0 \%$ & 0.0000 \\
\hline & & 1 & & & & \\
\hline & $>10$ & & $-0.011(-0.034,0.012)$ & - & $0.0 \%$ & 0.0000 \\
\hline
\end{tabular}

\subsubsection{Sensitivity analysis and publication bias}

Sensitivity analysis of the relationship between continuous exposure to PFOA and four liver enzyme indicators is shown in Table S6. Since most of the analyses did not substantially change the pooled effect estimates, we consider the results are stable to a certain extent. It is noteworthy that when we performed the meta-analysis under the quality effect model, all the above associations that were originally shown to be significant under the random effects model disappeared (Figures S1-S8). By Egger's test, we did not identify evidence of publication bias for the exposure-outcome combinations (Table 3). However, evidence from Doi plots and LFK index indicated that all the exposure-outcome combinations showed publication bias (Figure S21-S36).

\subsection{Confidence in the body of evidence and level of evidence}

Table S7 showed a summary of our confidence ratings for each exposure-outcome combination in the body of evidence. Based on the NTP/OHAT framework, only control and experimental studies were initially rated as "high confidence," but the majority of included observational studies with unmeasured risk of confounding would be rated as "moderate confidence" throughout the rating process, and a few other studies were assessed as "low confidence" due to low confidence in the risk of bias.

\section{Discussion}


To our knowledge, our study is the first meta-analysis and systematic review in the relevant field to incorporate all relevant cohort studies exploring the association of PFOA with liver enzyme indicators. The results of our cohort-based study support the hypothesis that PFOA increases the levels of four common liver enzymes, and this causal relationship was observed to the extent of the population-based study field. However, based on subgroup and descriptive analyses, we still detected that our included studies did not provide consistent strength of evidence support, and the heterogeneity of results across liver enzyme indicators and differences in the degree of adjustment for confounders were limiting factors in the interpretation of causality from our results (Table 4).

The hepatotoxic effects of PFOA in rodents leading to hepatomegaly and hepatocyte histological alterations have been well documented [43, 44], and although different mechanisms also play a role in humans, the PPAR-a agonist-mediated pathway remains one of the main mechanisms leading to altered expression of genes involved in peroxisome proliferation, cell cycle control and apoptosis, and this PPAR-a response has similarly predicted in human cellular responses [45-47]. Exposure to PFOA resulted in site-specific DNA methylation of the mTOR pathway inhibitor Pten gene, decreased gene expression and increased expression of Mtor and Kit, promoting apoptosis and liver injury [26]. The experiments with HepG2 cells cultured in vitro revealed that PFOA activated lipid metabolism genes, altered cellular metabolic rate, increased lipid deposition in hepatocytes, and exhibited great cytotoxicity [28]. PFOA disrupted the activity of metabolic detoxification enzyme CYP450 by blocking the interaction of nuclear translocation complexes with DNA sequences, affecting the conversion and excretion of toxic substances, which may lead to diminished hepatic detoxification [48]. One important mechanism of PFAS interference with fatty acid metabolism and lipid transport is the strong affinity for hepatic fatty acid binding proteins, showing intrinsic hepatotoxicity and bioaccumulation $[49,50]$.

Several studies have shown that PFOA is a specific risk factor with hepatotoxicity that affects the synthesis and metabolism of liver enzymes, and these studies compared associations between different indicators of liver functional impairment (e.g., liver enzymes, bilirubin, and abnormal lipid metabolism) at different levels of PFOA exposure, but most of this evidence comes from cross-sectional studies as well as cohort studies with small samples, there is a gap in systematic reviews and meta-analyses of longitudinal studies that quantify these associations. Similar to our results, $[9,15,29]$ reported that the relationship between PFOA exposure and ALT elevation (a proxy for hepatocyte injury) in longitudinal studies was consistent across analyses, specifically for for PFOA continuous consideration (per one In-unit increase) and quintile (from the first to the fifth quintile) for cumulative and year-specific serum PFOA, as well as for ALT continuous consideration (ALT level) or as dichotomous results (odds of above-normal ALT), significant relationships of increasing ALT were observed. In contrast, however, studies by $[12,14,38]$ suggested no clinical hepatotoxicity associated with PFOA levels, in contrast to previously reported observations. For AST, the existing conclusions of individual cohort studies were not harmonized, with three studies reporting that continuous exposure (per one unit or In-unit) to PFOA brought a significant increase from $0.25 \%$ [9] to $2.9 \%$ [13], while three other studies failed to reach a significance result [14, 29, 40]. The majority $(n=$ 4) of the six studies that currently examined PFOA and GGT reported the significant relationship with continuous exposure to PFOA [9, 10, 13, 29], while two other studies that examined the of the effects of community PFAS exposure similarly gave positive effect sizes $(0.003$ and 0.000$)$ although without statistical significance $[15,40]$. Among the four longitudinal studies that focused on the association between PFOA and ALP, only one study reported the significant association between continuous per one unit exposure to PFOA and an increase in ALP at the $0.73 \%$ level [13], and two studies respectively from the United States and China failed to generate a statistically significant association [9, 40], and [14] even reported a negative association of continuous per one In-unit exposure to PFOA with a $17.73 \%(-1.1750,-0.0007)$ decrease in ALP levels.

It is noteworthy that substantial and statistically significant heterogeneity was detected in the results of the available cohort analysis for the remaining three of our four liver enzyme indicators, except for ALP ( $n=4,0.007$, l-squared $=0.0 \%$ ) (Table 3$)$, and that there is substantial and inevitable heterogeneity in studies of liver function biomarkers related to environmental exposures that must be considered, as suggested by [30, 51]. Between-group heterogeneity may arise from the dose of PFOA exposure, statistical methods, different sample sizes, inconsistencies in geographic characteristics and the degree of adjustment for confounding factors (e.g., gender, age, alcohol intake, BMI, smoking history, etc.). This limits to some extent the interpretation of our results in terms of implications.

For the effects of combined exposure to different doses of PFOA, while higher PFAS concentrations are always associated with higher ALT in most crosssectional studies $[10,11,14,15,29,32]$, prospective studies have revealed the most null association [32, 52], it also indeed leads to differences in results, as described above $[9,53]$. There is still no consensus regarding the shape of the dose-response relationship curve between PFOA and liver enzyme indicators $[10$, $12,15,32]$, Kennedy et al. characterized sub-chronic and chronic toxicity studies in rodents, revealing the liver as the most sensitive target organ for PFOA action and the dose-dependent increase in serum ALP, ALT, and AST levels associated with PFOA administration [54], which has been verified in many animal experiments [43, 44, 55], however unlike rats and mice, no similar situation was observed in cynomolgus monkeys after oral dosing PFOA (6 months) [56]. While in population experiments, chronic exposure to community PFOA exposure among 371 residents from households who had resided in the Little Hocking Water Association district ([40], PFOA:354(184-571)/(ng/ml)), which is substantially higher than the average PFOA currently observed in general population samples in the United States, but they failed unexpectedly to find any significant positive relationship between serum (PFOA) and markers of liver function (including three classes of liver enzymes) and other markers with potential health effects; In another longitudinal evaluation of clinical parameters with PFOA levels (median) greater than $10 \mathrm{ng} / \mathrm{ml}$, similarly no adverse correlation was found between changes in clinical chemistry of PFOA (50.9 $\mathrm{ng} / \mathrm{ml}$ ), non-HDL cholesterol, HDL and liver enzyme indicators [14]; Another cohort-study from a high-tech fluorescent chemical industrial zone in Jiangsu, China, showed a different conclusion, with Wang et al. [38] measuring median serum PFOA and PFOS levels of $284.34 \mathrm{ng} / \mathrm{mL}$ and $34.16 \mathrm{ng} / \mathrm{mL}$ in residents and 1635.96 $\mathrm{ng} / \mathrm{mL}$ and $33.46 \mathrm{ng} / \mathrm{mL}$ in occupational participants, after adjusting for confounding, the significant increasing correlation of PFOA with AST was observed in workers $(0.2000,0.1000$ to 0.3000$)$, but not in ALT (-0.1700, -0.1900 to 0.0000$)$. Possible explanations for the discrepancy in their conclusions are strongly associated with their insufficient adjustment for confounding factors (especially some major confounders such as alcohol intake, smoking history, age, etc.) and their low RoB scores in all six domains including selection bias, making the quality of their evidence seriously dubious. The other five included cohort studies all measured PFOA levels below $10 \mathrm{ng} / \mathrm{ml}$ and showed the positive and significant correlation between PFOA exposure and ALT, except for the study by [12] (-0.3000, -0.7333 to 0.1667$)$; in ALP, [9] and [13] reported contradictory findings $(-0.0111,-0.0336$ to 0.0119 versus $0.0073,0.0028$ to 0.0118$)$, respectively; 
in AST, except for [29] $(0.18,-0.0400$ to 0.4000$)$, the other two studies reported significant increases; in GGT, the significant relationship was reported in four studies except for [15] $(0.0030,-0.0020$ to 0.0080$)$. In the absence of explicit prior statements about the dose-response relationship between PFOA and any sort of liver enzyme indicator, this variability strongly suggests a possible nonlinear relationship between them with stronger effects at low dose exposures, but further detailed studies are required.

Effect estimates in our meta-analysis are reported in describing comparisons per one unit or In-unit change, mainly considering that the available data are mainly clustered under this group. More importantly, Kerger et al. [57] demonstrated that classification by chemical dose level, such as utilizing the low exposure group as a valid control group for statistical comparisons of common disease states, raises significant difficulties in toxicological studies, possibly due to inadvertent selection bias that may have affected the lowest exposure quartile (control group), making the dose-response relationship between PFOA/PFOS and risk of outcome tenuous; also, we have attempted dose-response meta-analysis to investigate a possible dose-response relationship between PFOA and liver enzyme indicators, but the existing number of cohort studies was insufficient to extract the necessary data to proceed. Therefore, in aggregate, our approach is the most reasonable allowing consistent comparison of study-specific estimates and interpretation of findings at this stage.

In addition to the dosage differences mentioned above, which may account for much of the heterogeneity, regional socioeconomic status (SES) or potential sociodemographic predictors have emerged as potentially important confounding factors in environmental health studies [58], 7 of the 9 studies we ultimately analyzed for data synthesis were from the United States, with the exception of 2 from China, by simply classifying we can observe that the studies from China showed statistically significant associations for all three indicators (ALT, AST, GGT) except ALP, which can be moderately explained by the lower foundational health conditions, while the presence of publication bias for positive results must also be considered; the studies we included ranged from the largest sample size of 32254 [15] to the smallest of 74 [13], the effect of sample size on the results was not demonstrated explicitly in our subgroup and main analyses; other factors such as age and gender, given the small amount of evidence available for analysis, subgroup analyses cannot ensure the number of per group greater than 3 , which is insufficient to account for specific associations. Given the inherent limitations of epidemiological data, these estimates need to be interpreted with caution, although our study considers only the results of longitudinal cohort studies, which can show associations with respect to time and exclude the possibility of reverse causality to some extent $[9,14,38]$.

Gender differences in the association between PFAS and liver enzymes have barely been reported in the literature [15], and only one study of the nine cohorts we included attempted to explore differences between men and women by performing subgroup analyses by gender, Mora et al. [12] reported a prospective Boston area prenatal cohort that revealed in girls during childhood, higher levels of PFOS, PFOA concentrations were associated with deleterious changes (higher TC and/or LDL-C, higher HDL-C, and slightly lower ALT), unlike the differences in PFAS-lipid associations between males and females in different age groups [59-61] which have been widely reported. In the majority of cross-sectional as well as cohort studies, no clear relationship between PFOA exposure level and gender was found [15], but [38] reported differences in the gender distribution of two PFAS (PFTA and PFHxS), specifically higher dosages of exposure were observed in the male subgroup, an earlier NHANES studies also demonstrated higher mean concentrations of PFOS, PFOA and PFHxS in males than in females [17], the significant effect of PFAS and liver enzymes at low doses described above might be a reason to explain the sex differences. Considering the inevitable differences in lifestyle and exposure patterns such as product use, chemical plant work environment, etc. between the genders, further research on this topic is urgently needed.

The four liver enzyme indicators we selected can largely reflect the impairment of liver function [9, 12,14]. However, each individual index has its own differences in sensitivity and specificity, it is still challenging to reflect the status of liver function with differences in biomarker changes only, and it remains a hot topic whether the possible effects of PFAS are clinically significant compared to other risk factors for liver enzyme effects, specifically: higher ALT is a marker of hepatocyte dysfunction, and as one of the most common one of the liver function tests, with a reference value of less than 40 units, is the main diagnostic item for hepatocellular parenchymal damage, its high level often parallels the severity of the disease and is commonly used to screen children for nonalcoholic fatty liver disease (NAFLD) [62], but 1) there is a lack of consistency between changes in ALT activity and pathological histological changes in the liver, some patients with severe liver damage do not have elevated ALT; 2 ) ALT suffers from the lack of specificity, and there are various reasons that can cause changes in hepatocyte membrane permeability, such as: fatigue, alcohol consumption, colds and even emotional factors; the normal value of AST is $0-$ $37 \mu / L$, but it is present in hepatocytes and cardiomyocytes at the same time, and even the levels in cardiomyocytes are higher than in hepatocytes, which largely limits its application, and in clinical work we often combine AST with ALT, when ALT is significantly elevated with the ratio (also known as De Ritis ratio) of glutathione (AST)/glutathione (ALT) > 1, it indicates damage to the liver parenchyma and can also be used as an auxiliary test for myocardial infarction and myocarditis [63-65]; the normal participation value of ALP is 30-90u/L, and the increased level represents impaired biliary excretion in the intrahepatic biliary tract, which is mainly used for obstructive jaundice, primary hepatocellular carcinoma, secondary hepatocellular carcinoma, cholestatic hepatitis, etc. However, this enzyme is also active in bone tissue, and serum ALP can also be elevated in pregnant women, healing fractures, osteochondrosis, osteoporosis, leukemia, and hyperthyroidism; GGT is very low in healthy human serum (less than 40 units), mainly from the liver, with slightly produced by the kidney, pancreas, and small intestine, and GGT is not as good as ALT in reflecting necrotic damage to hepatocytes, and 1) GGT is not as good as ALT in reflecting the necrotic damage of liver cells, but it can be used to distinguish jaundice caused by internal and external liver obstruction, 2) acute and chronic viral hepatitis, cirrhosis, 3) acute and chronic alcoholic hepatitis and drug-related hepatitis: GGT can be significantly or moderately elevated (300-1000 U/L), while ALT and AST are only mildly elevated or even normal, 4) alcoholics can have their GGT decreased after they stop drinking, 5) GGT can also be elevated in other toxic liver disease, fatty liver, liver tumors. Thus, even though we simultaneously found that PFOA exposure resulted in elevated levels of all four liver enzymes and was able to suggest a state of hepatic impairment as assessed by quality of evidence as well as bias analysis, it is still challenging to point specifically to a specific hepatic impairment disease.

Pending exploration of whether such exposure to long-chain compounds (e.g., 9-carbon PFNA) may increase liver enzyme levels is particularly important for the implementation of more stringent regulation of long-chain PFAS [66, 67], and future studies should pay attention to the effects of long-chain PFAS as well as the potential mechanisms $[68,69]$. 
Notably, the results of the meta-analysis under the random effects model and the quality effects model were inconsistent, cutting all the statistically significant combinations. The conflicting results suggest that the need for further research to expanded number of studies and determine the relationship between each exposure and outcome.

\section{Strengths And Limitations}

This study provides the most recent and comprehensive cohort-based review of the evidence on the relationship between PFOA and the four most used liver enzyme indicators. The major strengths of this study are the integration of the most up-to-date research evidence and broad coverage of all longitudinal studies with rigorous, transparent, and reproducible assessment of the evidence and standardized data processing methods that preserve the originality of the data as much as possible, giving a comprehensive and systematic elucidation of the potential role of PFOA exposure in increasing liver enzyme levels. This study makes a timely contribution to a rapidly evolving field of research, illuminates the changes facing meta-analysis, and provides suggestions for improving the potential utility of further studies.

Nevertheless, our study still has limitations that characterize the lack of research in this area and the remaining open questions that need to be addressed, as detailed below:

- We considered only one type of PFAS, considering that most long-chain PFAS (e.g., PFTrDA, PFTeDA) as well as short-chain congeners and functionalized perfluoropolyether as substitutes (e.g., chlorinated polyfluoroalkyl ether sulfonic acids (Cl-PFESAs) or F-53B) are of restricted relevance [70], and additionally Nian et al. [9] revealed that PFOA isomers (straight or branched chains) differences in the relationship with liver enzyme indicators, future studies should focus on the effects of different dose responses and different types of PFAS.

- For further grouping of different categories of data (continuous versus categorical), there are still many exposure-outcome combinations less than 2 studies, the limited data prevented us from conducting a meta-analysis to examine these associations.

- Given the strong correlation found between PFAS, PFOA may co-exist and play a combined role with other PFAS, so the effects we detected may be the result of exposure to multiple PFASs and need to be understood by further studies.

- Liver function biomarkers are only captured at one time point and some of them, such as ALT, are less specific and sensitive and can be influenced by other factors (e.g., exertion, emotion), which may lead to misclassification of findings in cross-sectional as well as transient marker values.

- Results based on biomarkers rather than liver biopsies remain a challenge in reflecting liver function as well as specific disease, and liver biopsies would be the gold standard validation test for patients with clinically significant liver disease, and further health studies would benefit from the use of more comprehensive liver function assessments, including measurement of other liver function markers (e.g., albumin, total bilirubin, and lipid metabolism markers), and/or liver imaging techniques.

- The representativeness of the study results could still be improved, the type and prevalence of liver function impairment is closely related to the level of public health prevention and control as well as the economic and sociocultural aspects of the area of residence. However, the majority (7/9) of our nine publications currently included were from the United States, a developed country/region, which limits the generalizability of the findings. Future studies may have to supplement to assess the impact of PFOA emissions on liver enzymes in these countries with weak infrastructure, lower economic levels, and less developed health care insurance mechanisms.

- Although potential confounders were controlled for as much as possible in the included studies together with subgroup analyses, the effects of unknown or unmeasured confounders such as sex, age, and alcohol intake could not be measured in detail in our summary effect estimates.

- Given the limited amount of evidence observed, future studies should aim to elucidate the associations in age and gender.

- In addition, the association between changes in liver enzyme markers and high serum PFOA may be due to "reverse causality" [71], even in longitudinal studies, subtle pharmacokinetic differences can lead to differences in biomarkers of exposure and liver impairment, it is possible that an undetermined reverse causality exists [12], all of which could affect the feasibility of conclusions, and further studies should be conducted with a standardized longitudinal cohort study design.

\section{Conclusions}

We conducted the first meta-analysis and systematic review based on a longitudinal cohort study confirming the effect of PFOA exposure on liver enzyme indicators in humans, which demonstrated that PFOA exposure showed a statistically significant association with increased levels of four liver enzyme indicators, accompanied by some heterogeneity. Further clinical or epidemiological studies, especially longitudinal studies, are needed to expand the sample size and further identify the effects of different types and dosages of confounding factors of PFOA exposure on liver enzyme indicators, which are essential to verify the evidence of causality and clear dose-response curves. In addition, future studies should use mediation analysis with full consideration of gender, age and other confounders and reverse causality.

\section{Declarations}

\section{Ethics approval and consent to participate}

Not Applicable.

\section{Consent for publication}

The manuscript have been seen and approved for submitting to "Environmental Health" by all authors. 
Availability of data and materials

Not Applicable.

\section{Competing interests}

The authors declare that they have no known competing financial interests or personal relationships that could have appeared to influence the work reported in this paper.

Funding

This study was supported by Anhui Medical University (2019xkj019), Key Projects of Natural Science Research of Anhui Provincial Department of Education (No. KJ2020A0163), and National Natural Science Foundation of China (82070986).

Authors' contributions

All authors contributed to the concept and design of the study, the review and revision of the article, and have approved the final version of the paper. Tian-Qi Wang carried out the database search and drafted the article.

\section{Acknowledgements}

We thank the editorial team and anonymous referees for helpful comments. So, the views expressed herein are of the authors. We thank Editage for editorial assistance.

\section{References}

1. Wang T, Wang P, Meng J, Liu S, Lu Y, Khim JS, Giesy JP: A review of sources, multimedia distribution and health risks of perfluoroalkyl acids (PFAAs) in China. Chemosphere 2015, 129:87-99.

2. VanNoy BN, Lam J, Zota AR: Breastfeeding as a Predictor of Serum Concentrations of Per-and Polyfluorinated Alkyl Substances in Reproductive-Aged Women and Young Children: A Rapid Systematic Review. Curr Environ Health Rep 2018, 5(2):213-224.

3. Kato K, Wong LY, Jia LT, Kuklenyik Z, Calafat AM: Trends in exposure to polyfluoroalkyl chemicals in the U.S. Population: 1999-2008. Environ Sci Technol 2011, 45(19):8037-8045.

4. Woods MM, Lanphear BP, Braun JM, McCandless LC: Gestational exposure to endocrine disrupting chemicals in relation to infant birth weight: a Bayesian analysis of the HOME Study. Environ Health 2017, 16(1):115.

5. Negri E, Metruccio F, Guercio V, Tosti L, Benfenati E, Bonzi R, La Vecchia C, Moretto A: Exposure to PFOA and PFOS and fetal growth: a critical merging of toxicological and epidemiological data. Critical reviews in toxicology 2017, 47(6):482-508.

6. Eriksen KT, Raaschou-Nielsen O, Sorensen M, Roursgaard M, Loft S, Moller P: Genotoxic potential of the perfluorinated chemicals PFOA, PFOS, PFBS, PFNA and PFHXA in human HepG2 cells. Mutation research 2010, 700(1-2):39-43.

7. Gonzalez FJ, Shah YM: PPARalpha: mechanism of species differences and hepatocarcinogenesis of peroxisome proliferators. Toxicology 2008, 246(1):28.

8. Gallo V, Leonardi G, Genser B, Lopez-Espinosa MJ, Frisbee SJ, Karlsson L, Ducatman AM, Fletcher T: Serum perfluorooctanoate (PFOA) and perfluorooctane sulfonate (PFOS) concentrations and liver function biomarkers in a population with elevated PFOA exposure. Environmental health perspectives 2012, 120(5):655-660.

9. Nian M, Li QQ, Bloom M, Qian ZM, Syberg KM, Vaughn MG, Wang SQ, Wei Q, Zeeshan M, Gurram N et al: Liver function biomarkers disorder is associated with exposure to perfluoroalkyl acids in adults: Isomers of C8 Health Project in China. Environ Res 2019, 172:81-88.

10. Lin CY, Lin LY, Chiang CK, Wang WJ, Su YN, Hung KY, Chen PC: Investigation of the associations between low-dose serum perfluorinated chemicals and liver enzymes in US adults. Am J Gastroentero/ 2010, 105(6):1354-1363.

11. Gleason JA, Post GB, Fagliano JA: Associations of perfluorinated chemical serum concentrations and biomarkers of liver function and uric acid in the US population (NHANES), 2007-2010. Environmental research 2015, 136:8-14.

12. Mora AM, Fleisch AF, Rifas-Shiman SL, Woo Baidal JA, Pardo L, Webster TF, Calafat AM, Ye X, Oken E, Sagiv SK: Early life exposure to per- and polyfluoroalkyl substances and mid-childhood lipid and alanine aminotransferase levels. Environment internationa/ 2018, 111:1-13.

13. Olsen GW, Burris JM, Burlew MM, Mandel JH: Plasma cholecystokinin and hepatic enzymes, cholesterol and lipoproteins in ammonium perfluorooctanoate production workers. Drug Chem Toxicol 2000, 23(4):603-620.

14. Olsen GW, Ehresman DJ, Buehrer BD, Gibson BA, Butenhoff JL, Zobel LR: Longitudinal assessment of lipid and hepatic clinical parameters in workers involved with the demolition of perfluoroalkyl manufacturing facilities. J Occup Environ Med 2012, 54(8):974-983.

15. Darrow LA, Groth AC, Winquist A, Shin HM, Bartell SM, Steenland K: Modeled Perfluorooctanoic Acid (PFOA) Exposure and Liver Function in a Mid-Ohio Valley Community. Environmental health perspectives 2016, 124(8):1227-1233.

16. Strynar M, Dagnino S, McMahen R, Liang S, Lindstrom A, Andersen E, McMillan L, Thurman M, Ferrer I, Ball C: Identification of Novel Perfluoroalkyl Ether Carboxylic Acids (PFECAs) and Sulfonic Acids (PFESAs) in Natural Waters Using Accurate Mass Time-of-Flight Mass Spectrometry (TOFMS).

Environmental science \& technology 2015, 49(19):11622-11630. 
17. Calafat AM, Wong LY, Kuklenyik Z, Reidy JA, Needham LL: Polyfluoroalkyl chemicals in the U.S. population: data from the National Health and Nutrition Examination Survey (NHANES) 2003-2004 and comparisons with NHANES 1999-2000. Environmental health perspectives 2007, 115(11):1596-1602.

18. Li Y, Oliver DP, Kookana RS: A critical analysis of published data to discern the role of soil and sediment properties in determining sorption of per and polyfluoroalkyl substances (PFASs). The Science of the total environment 2018, 628-629:110-120.

19. Barry V, Darrow LA, Klein M, Winquist A, Steenland K: Early life perfluorooctanoic acid (PFOA) exposure and overweight and obesity risk in adulthood in a community with elevated exposure. Environmental research 2014, 132:62-69.

20. Bertolini A, van de Peppel IP, Bodewes F, Moshage H, Fantin A, Farinati F, Fiorotto R, Jonker JW, Strazzabosco M, Verkade HJ et al: Abnormal Liver Function Tests in Patients With COVID-19: Relevance and Potential Pathogenesis. Hepatology 2020, 72(5):1864-1872.

21. Bangash MN, Patel J, Parekh D: COVID-19 and the liver. little cause for concern. The lancet Gastroenterology \& hepatology 2020, 5(6):529-530.

22. Huang J, Lin S, Wang M, Wan B, Zhu Y: Syphilitic hepatitis: a case report and review of the literature. BMC gastroenterology 2019, 19(1):191.

23. Xu L, Nagata N, Ota T: Glucoraphanin: a broccoli sprout extract that ameliorates obesity-induced inflammation and insulin resistance. Adipocyte 2018, 7(3):218-225.

24. Guan WJ, Ni ZY, Hu Y, Liang WH, Ou CQ, He JX, Liu L, Shan H, Lei CL, Hui DSC et al: Clinical Characteristics of Coronavirus Disease 2019 in China. The New England journal of medicine 2020, 382(18):1708-1720.

25. Kothari S, Dhami-Shah H, Shah SR: Antidiabetic Drugs and Statins in Nonalcoholic Fatty Liver Disease. Journal of clinical and experimental hepatology 2019, 9(6):723-730.

26. Wen Y, Chen J, Li J, Arif W, Kalsotra A, Irudayaraj J: Effect of PFOA on DNA Methylation and Alternative Splicing in Mouse Liver. Toxicology letters 2020, 329:38-46.

27. Franco ME, Sutherland GE, Fernandez-Luna MT, Lavado R: Altered expression and activity of phase I and II biotransformation enzymes in human liver cells by perfluorooctanoate (PFOA) and perfluorooctane sulfonate (PFOS). Toxicology 2020, 430:152339.

28. Wen Y, Mirji N, Irudayaraj J: Epigenetic toxicity of PFOA and GenX in HepG2 cells and their role in lipid metabolism. Toxicology in vitro : an international journal published in association with BIBRA 2020, 65:104797.

29. Olsen GW, Zobel LR: Assessment of lipid, hepatic, and thyroid parameters with serum perfluorooctanoate (PFOA) concentrations in fluorochemical production workers. Int Arch Occup Environ Health 2007, 81(2):231-246.

30. Jain RB: Concentration of selected liver enzymes across the stages of glomerular function: the associations with PFOA and PFOS. Heliyon 2019, 5(7):e02168.

31. Steenland K, Zhao L, Winquist A: A cohort incidence study of workers exposed to perfluorooctanoic acid (PFOA). Occupational and environmental medicine 2015, 72(5):373-380.

32. Sakr CJ, Kreckmann KH, Green JW, Gillies PJ, Reynolds JL, Leonard RC: Cross-sectional study of lipids and liver enzymes related to a serum biomarker of exposure (ammonium perfluorooctanoate or APFO) as part of a general health survey in a cohort of occupationally exposed workers. Journal of occupational and environmental medicine 2007, 49(10):1086-1096.

33. Liberati A, Altman DG, Tetzlaff J, Mulrow C, Gotzsche PC, loannidis JP, Clarke M, Devereaux PJ, Kleijnen J, Moher D: The PRISMA statement for reporting systematic reviews and meta-analyses of studies that evaluate healthcare interventions: explanation and elaboration. BMJ 2009, 339:b2700.

34. Andersen IB, Andreassen M, Krogh J: The effect of dopamine agonists on metabolic variables in adults with type 2 diabetes: A systematic review with meta analysis and trial sequential analysis of randomized clinical trials. Diabetes, obesity \& metabolism 2021, 23(1):58-67.

35. Sutton P, Kavanaugh-Lynch MH, Plumb M, Yen IH, Sarantis H, Thomsen CL, Campleman S, Galpern E, Dickenson C, Woodruff TJ: California Breast Cancer Prevention Initiatives: Setting a research agenda for prevention. Reprod Toxico/ 2015, 54:11-18.

36. Cano-Sancho G, Ploteau S, Matta K, Adoamnei E, Louis GB, Mendiola J, Darai E, Squifflet J, Le Bizec B, Antignac JP: Human epidemiological evidence about the associations between exposure to organochlorine chemicals and endometriosis: Systematic review and meta-analysis. Environment international 2019, 123:209-223.

37. Tian YP, Zeng XW, Bloom MS, Lin S, Wang SQ, Yim SHL, Yang M, Chu C, Gurram N, Hu LW et al: Isomers of perfluoroalkyl substances and overweight status among Chinese by sex status: Isomers of C8 Health Project in China. Environment international 2019, 124:130-138.

38. Wang J, Zhang Y, Zhang W, Jin Y, Dai J: Association of perfluorooctanoic acid with HDL cholesterol and circulating miR-26b and miR-199-3p in workers of a fluorochemical plant and nearby residents. Environmental science \& technology 2012, 46(17):9274-9281.

39. Mora MA, Araya JE: Semi-automatic Extraction of Plants Morphological Characters from Taxonomic Descriptions Written in Spanish. Biodiversity data journal 2018(6):e21282.

40. Emmett EA, Zhang H, Shofer FS, Freeman D, Rodway NV, Desai C, Shaw LM: Community exposure to perfluorooctanoate: relationships between serum levels and certain health parameters. Journal of occupational and environmental medicine 2006, 48(8):771-779.

41. (OHAT) OoHAaT, Program DotNT, Sciences NloEH: Handbook for Conducting a Literature-Based Health Assessment Using OHAT Approach for Systematic Review and Evidence Integration. In.; March 4, 2019.

42. Guyatt GH, Oxman AD, Kunz R, Brozek J, Alonso-Coello P, Rind D, Devereaux PJ, Montori VM, Freyschuss B, Vist G et al: GRADE guidelines 6. Rating the quality of evidence-imprecision. Journal of clinical epidemiology 2011, 64(12):1283-1293.

43. Qazi MR, Abedi MR, Nelson BD, DePierre JW, Abedi-Valugerdi M: Dietary exposure to perfluorooctanoate or perfluorooctane sulfonate induces hypertrophy in centrilobular hepatocytes and alters the hepatic immune status in mice. International immunopharmacology 2010, 10(11):1420-1427.

44. Lau C, Anitole K, Hodes C, Lai D, Pfahles-Hutchens A, Seed J: Perfluoroalkyl acids: a review of monitoring and toxicological findings. Toxicological sciences : an official journal of the Society of Toxicology 2007, 99(2):366-394.

Page $15 / 18$ 
45. Bjork JA, Butenhoff JL, Wallace KB: Multiplicity of nuclear receptor activation by PFOA and PFOS in primary human and rodent hepatocytes. Toxicology 2011, 288(1-3):8-17.

46. Rakhshandehroo M, Hooiveld G, Muller M, Kersten S: Comparative analysis of gene regulation by the transcription factor PPARalpha between mouse and human. PloS one 2009, 4(8):e6796.

47. Yang Q, Nagano T, Shah Y, Cheung C, Ito S, Gonzalez FJ: The PPAR alpha-humanized mouse: a model to investigate species differences in liver toxicity mediated by PPAR alpha. Toxicological sciences : an official journal of the Society of Toxicology 2008, 101(1):132-139.

48. Zhou SF, Wang B, Yang LP, Liu JP: Structure, function, regulation and polymorphism and the clinical significance of human cytochrome P450 1A2. Drug metabolism reviews 2010, 42(2):268-354.

49. Chen A, Tang Y, Davis V, Hsu FF, Kennedy SM, Song H, Turk J, Brunt EM, Newberry EP, Davidson NO: Liver fatty acid binding protein (L-Fabp) modulates murine stellate cell activation and diet-induced nonalcoholic fatty liver disease. Hepatology 2013, 57(6):2202-2212.

50. Cao H, Zhou Z, Wang L, Liu G, Sun Y, Wang Y, Wang T, Liang Y: Screening of Potential PFOS Alternatives To Decrease Liver Bioaccumulation: Experimental and Computational Approaches. Environmental science \& technology 2019, 53(5):2811-2819.

51. Attanasio R: Sex differences in the association between perfluoroalkyl acids and liver function in US adolescents: Analyses of NHANES $2013-2016$. Environmental pollution 2019, 254(Pt B):113061.

52. Costa G, Sartori S, Consonni D: Thirty years of medical surveillance in perfluooctanoic acid production workers. Journal of occupational and environmental medicine 2009, 51(3):364-372.

53. Wang Y, Yao J, Dai J, Ma L, Liu D, Xu H, Cui Q, Ma J, Zhang H: Per- and polyfluoroalkyl substances (PFASs) in blood of captive Siberian tigers in China: Occurrence and associations with biochemical parameters. Environmental pollution 2020, 265(Pt B):114805.

54. Kennedy GL, Jr., Hall GT, Brittelli MR, Barnes JR, Chen HC: Inhalation toxicity of ammonium perfluorooctanoate. Food and chemical toxicology : an international journal published for the British Industrial Biological Research Association 1986, 24(12):1325-1329.

55. Abdellatif A, Al-Tonsy AH, Awad ME, Roberfroid M, Khan MN: Peroxisomal enzymes and 8-hydroxydeoxyguanosine in rat liver treated with perfluorooctanoic acid. Disease markers 2003, 19(1):19-25.

56. Butenhoff J, Costa G, Elcombe C, Farrar D, Hansen K, Iwai H, Jung R, Kennedy G, Jr., Lieder P, Olsen G et al: Toxicity of ammonium perfluorooctanoate in male cynomolgus monkeys after oral dosing for 6 months. Toxicological sciences : an official journal of the Society of Toxicology 2002, 69(1):244-257.

57. Kerger BD, Copeland TL, DeCaprio AP: Tenuous dose-response correlations for common disease states: case study of cholesterol and perfluorooctanoate/sulfonate (PFOAPFOS) in the C8 Health Project. Drug and chemical toxicology 2011, 34(4):396-404.

58. Cai K, Song Q, Peng S, Yuan W, Liang Y, Li J: Uncovering residents' behaviors, attitudes, and WTP for recycling e-waste: a case study of Zhuhai city, China. Environmental science and pollution research international 2020, 27(2):2386-2399.

59. Eriksen KT, Raaschou-Nielsen O, McLaughlin JK, Lipworth L, Tjonneland A, Overvad K, Sorensen M: Association between plasma PFOA and PFOS levels and total cholesterol in a middle-aged Danish population. PloS one 2013, 8(2):e56969.

60. Frisbee SJ, Shankar A, Knox SS, Steenland K, Savitz DA, Fletcher T, Ducatman AM: Perfluorooctanoic acid, perfluorooctanesulfonate, and serum lipids in children and adolescents: results from the C8 Health Project. Archives of pediatrics \& adolescent medicine 2010, 164(9):860-869.

61. Maisonet M, Nayha S, Lawlor DA, Marcus M: Prenatal exposures to perfluoroalkyl acids and serum lipids at ages 7 and 15 in females. Environment international 2015, 82:49-60.

62. Saneian H, Khalilian L, Heidari-Beni M, Khademian M, Famouri F, Nasri P, Hassanzadeh A, Kelishadi R: Effect of I-camitine supplementation on children and adolescents with nonalcoholic fatty liver disease (NAFLD): a randomized, triple-blind, placebo-controlled clinical trial. Journal of pediatric endocrinology \& metabolism : JPEM 2021, 34(7):897-904.

63. Weng SF, Kai J, Guha IN, Qureshi N: The value of aspartate aminotransferase and alanine aminotransferase in cardiovascular disease risk assessment. Open heart 2015, 2(1):e000272.

64. Gao F, Chen C, Lu J, Zheng J, Ma XC, Yuan XY, Huo K, Han JF: De Ritis ratio (AST/ALT) as an independent predictor of poor outcome in patients with acute ischemic stroke. Neuropsychiatric disease and treatment 2017, 13:1551-1557.

65. Liu Y, Zhao P, Cheng M, Yu L, Cheng Z, Fan L, Chen C: AST to ALT ratio and arterial stiffness in non-fatty liver Japanese population:a secondary analysis based on a cross-sectional study. Lipids in health and disease 2018, 17(1):275.

66. Sharp S, Sardina P, Metzeling L, McKenzie R, Leahy P, Menkhorst P, Hinwood A: Per- and Polyfluoroalkyl Substances in Ducks and the Relationship with Concentrations in Water, Sediment, and Soil. Environmental toxicology and chemistry 2021, 40(3):846-858.

67. Schultes L, Sandblom O, Broeg K, Bignert A, Benskin JP: Temporal Trends (1981-2013) of Per- and Polyfluoroalkyl Substances and Total Fluorine in Baltic cod (Gadus morhua). Environmental toxicology and chemistry 2020, 39(2):300-309.

68. Gagliano E, Sgroi M, Falciglia PP, Vagliasindi FGA, Roccaro P: Removal of poly-and perfluoroalkyl substances (PFAS) from water by adsorption: Role of PFAS chain length, effect of organic matter and challenges in adsorbent regeneration. Water research 2020, 171:115381.

69. Lenka SP, Kah M, Padhye LP: A review of the occurrence, transformation, and removal of poly- and perfluoroalkyl substances (PFAS) in wastewater treatment plants. Water research 2021, 199:117187.

70. Shi Y, Vestergren R, Xu L, Zhou Z, Li C, Liang Y, Cai Y: Human Exposure and Elimination Kinetics of Chlorinated Polyfluoroalkyl Ether Sulfonic Acids (ClPFESAs). Environmental science \& technology 2016, 50(5):2396-2404.

71. Dhingra R, Winquist A, Darrow LA, Klein M, Steenland K: A Study of Reverse Causation: Examining the Associations of Perfluorooctanoic Acid Serum Levels with Two Outcomes. Environmental health perspectives 2017, 125(3):416-421. 
Figures

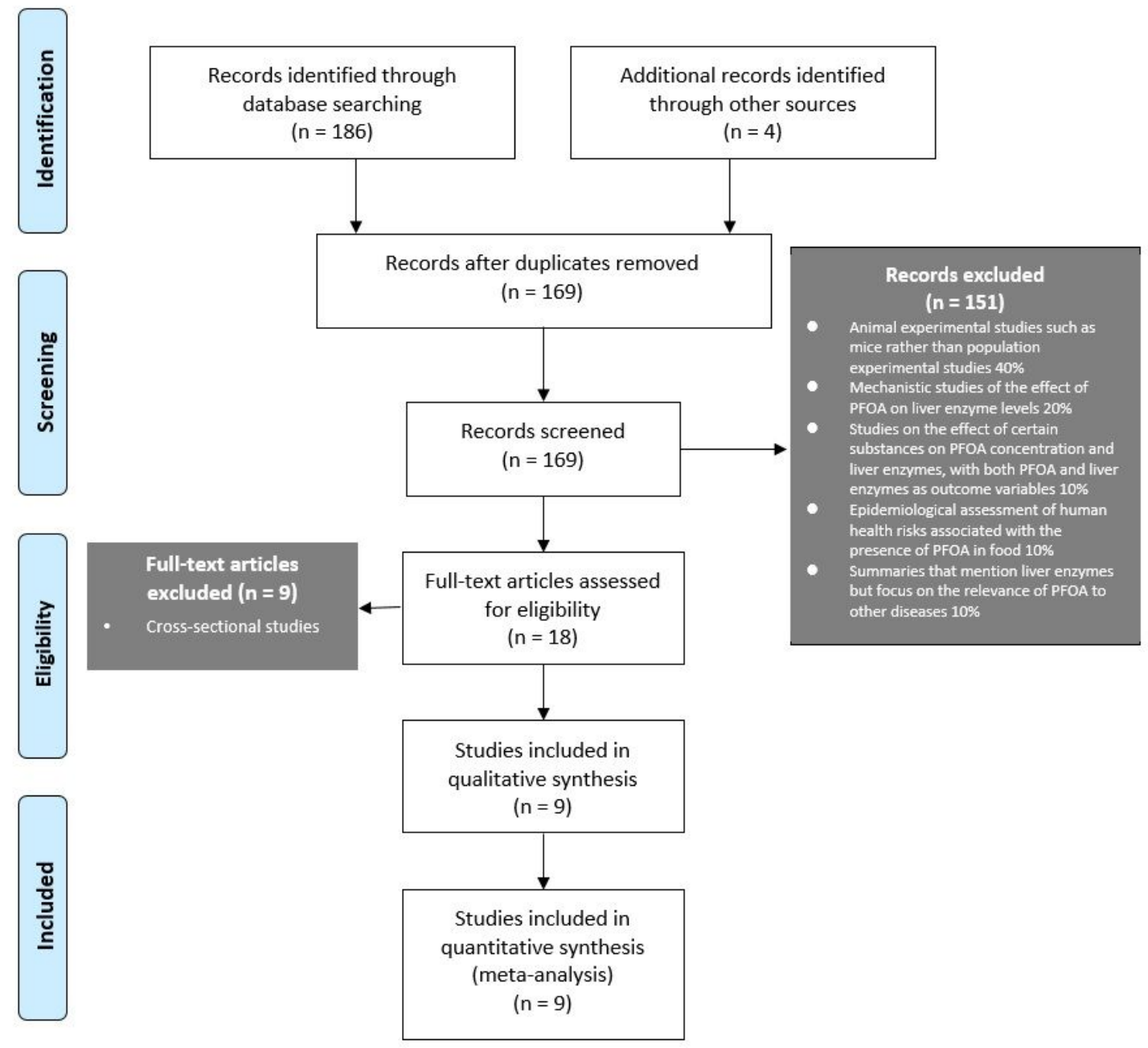

Figure 1

Flow diagram of study selection process. 

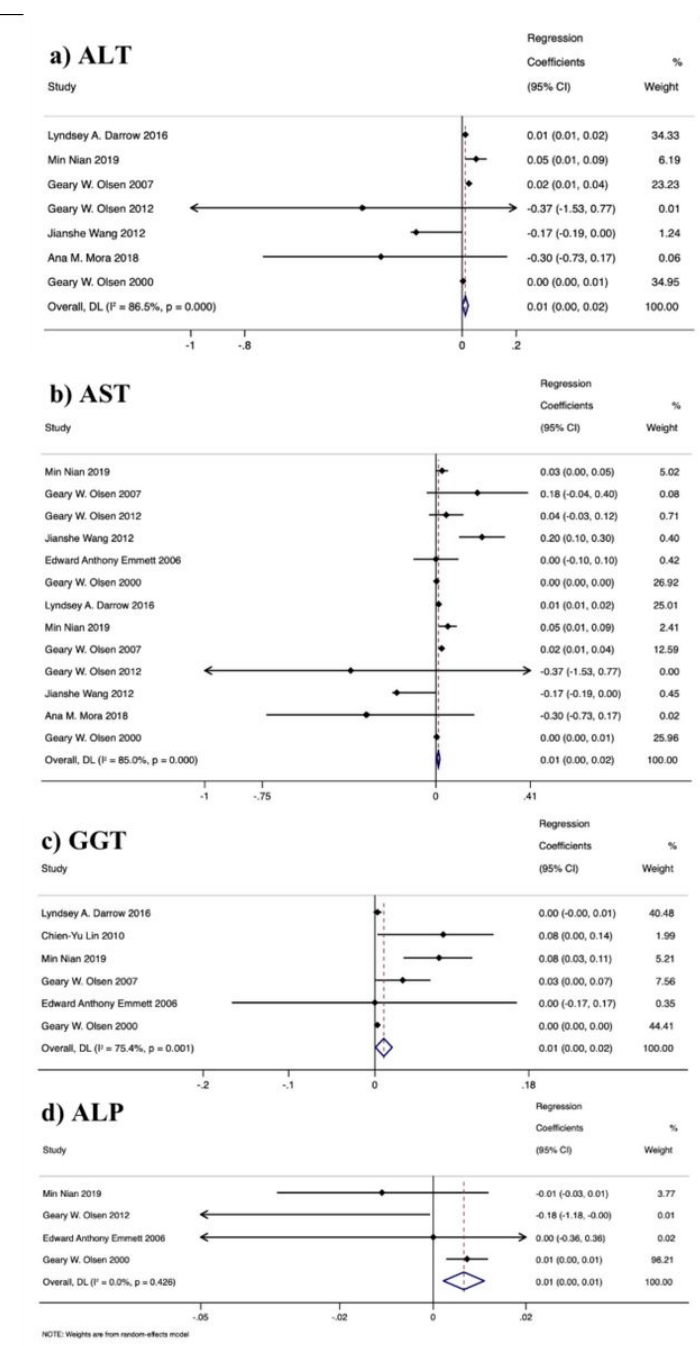

Figure 2

Meta-analysis of the associations of PFOA with ALT, AST, GGT and ALP for per $1 \mathrm{ng} / \mathrm{ml}$ increase.

\section{Supplementary Files}

This is a list of supplementary files associated with this preprint. Click to download.

- SupplementarymaterialsA.docx

- SupplementarymaterialsB.xlsx 